\title{
Estímulos químico e mecânico na rustificação de mudas de eucalipto ${ }^{1}$
}

\author{
Paulo Ricardo Lima ${ }^{2}$, Ubirajara Contro Malavasi ${ }^{2}$, João Alexandre Lopes Dranski ${ }^{3}$, \\ Marlene de Matos Malavasi ${ }^{2}$, Augustinho Borsoi ${ }^{4}$, Martios Ecco ${ }^{5}$
}

$10.1590 / 0034-737 X 201865050007$

\begin{abstract}
RESUMO
Para o sucesso do plantio a campo e o êxito de um povoamento florestal, faz-se necessário o uso de mudas florestais que apresentem bom desempenho após o plantio. Este estudo objetivou avaliar a qualidade de mudas de eucalipto, após rustificação com aplicação de ácido jasmônico (JA) e flexões caulinares. O experimento foi realizado em duas etapas, sendo a primeira desenvolvida em ambiente protegido e a segunda realizada a campo. O delineamento experimental foi inteiramente ao acaso, com sete tratamentos (testemunha; 2,0; 4,0; 6,0 e 8,0 $\mu \mathrm{mol} \mathrm{L}^{-1} \mathrm{de} \mathrm{JA}$, aplicados semanalmente, por quatro semanas; 20 e 40 flexões caulinares diárias, por quatro semanas), com cinco repetições. Após as quatro semanas de aplicação dos tratamentos, foram determinados os incrementos de altura, de diâmetro do coleto e de número de folhas, de massas de matérias secas das raízes e da parte aérea, de potencial de regeneração de raízes e de índice SPAD. Aos 90 dias após o plantio, foram avaliados os incrementos de altura e de diâmetro do coleto e a relação altura/diâmetro das mudas. A análise de agrupamento por UPGMA evidenciou a formação de três grupos: grupo 1 (testemunha, 2,0; 4,0 e 6,0 $\mathrm{mol} \mathrm{L}^{-1} \mathrm{de} \mathrm{JA}$ ); grupo 2 ( $8,0 \mu \mathrm{mol} \mathrm{L}^{-1} \mathrm{de} \mathrm{JA}$ ) e grupo 3 (flexões caulinares). Mudas que apresentaram maior incremento de altura e de número de folhas (grupos I e II), durante a fase de rustificação, apresentaram maiores incrementos de altura e de diâmetro do coleto a campo, aos 90 dias após o plantio. Parâmetros como incrementos de diâmetro do coleto, de potencial de regeneração de raízes e de SPAD, quantificados durante a rustificação de mudas no viveiro, não são preditivos de maior desempenho a campo.
\end{abstract}

Palavras-chave: ácido jasmônico; flexões caulinares; qualidade de mudas; clone 1528.

\section{ABSTRACT}

\section{Chemical and mechanical stimulation in the hardening of eucalyptus seedlings}

The objective of this work was to evaluate the quality of eucalyptus clone 1528 seedlings after hardening with application of jasmonic acid (JA) and stem bending. The experiment was conducted in two stages: the first, in a protected environment, and the second, in the field. A completely randomized experimental design with seven treatments (control, 2.0, 4.0, 6.0, and $8.0 \mathrm{imol} \mathrm{L} \mathrm{m}^{-1}$ of JA applied weekly for four weeks and 20 and 40 daily push-ups for four weeks) and five replicates of twenty seedlings. At the end of the treatments, the increase in height, root collar diameter, number of leaves, root and shoot dry matter, and relative chlorophyll index (SPAD) were determined. At 90 days after planting (field), the increases in height and root collar diameter and the height/diameter ratio of the seedlings were evaluated. A clustering analysis by UPGMA showed a formation of three groups: group 1 (control, 2.0, 4.0, and 6.0 ìmol L-1 of JA), group 2 ( 8.0 ìmol L-1 of JA), and group 3 (stem bending). Seedlings that showed the greatest increase in height and

Submetido em 14/03/2018 e aprovado em 10/09/2018

${ }^{1}$ Este trabalho é parte da Tese de doutorado do primeiro autor.

2Universidade Estadual do Oeste do Paraná, Marechal Cândido Rondon, Paraná, Brasil.paulorikardoo@hotmail.com; biramalavasi@yahoo.com.br; marlenemalavasi@yahoo.com.br

3 Centro Universitário Dinâmica das Cataratas, Faculdade Educacional de Medianeira, Medianeira, Paraná, Brasil. joaodranski@yahoo.com.br

${ }^{4}$ Centro Universitário Fundação Assis Gurgacz, Cascavel, Paraná, Brasil. augustinho.borsoi@outlook.com

Pontifícia Universidade Católica do Paraná, Toledo, Paraná, Brasil. ecco.martios@pucpr.br

*Autor para correspondência: paulorikardoo@hotmail.com 
number of leaves (groups I and II) during the hardening phase obtained higher increase in height and in the root collar diameter in the field at 90 days after planting. Parameters such as increase in root collar diameter, root regeneration potential, and SPAD quantified during the hardening of seedlings in the nursery are not predictive of higher performance in the field.

Keywords: jasmonic acid; stem flexures; quality of seedlings; clone 1528.

\section{INTRODUÇÃO}

Para o sucesso do plantio a campo e o êxito de um povoamento florestal, faz-se necessário o uso de mudas florestais que apresentem bom desempenho após o plantio. A identificação do padrão de rusticidade de mudas para implantação no viveiro, a fim de melhorar seu desempenho, entretanto, tem-se tornado um desafio para muitas empresas florestais.

Dificuldades no estabelecimento de técnicas padrões e de recomendações para a obtenção de mudas de qualidade acarretam mortalidade pós-plantio. Dessa forma, a produção de mudas resistentes, capacitadas a sobreviverem a campo, é uma das possíveis alternativas para minimizar as perdas pós-plantio. Sabe-se que a qualidade de mudas florestais baseia-se numa série de características morfofisiológicas que, especialmente, relacionam-se com a sobrevivência e o desenvolvimento a campo e, consequentemente, com o sucesso de plantios florestais.

Vários autores indicam que algumas práticas, como a submissão de mudas a estímulos mecânicos e a aplicação de reguladores vegetais, podem estar relacionadas com a rusticidade de espécies lenhosas (Oro et al., 2011; Dranski, 2013; Mazzuchelli et al., 2014; Gonçalves et al., 2015). Assim, essas práticas poderiam ser incluídas na rotina dos viveiros, favorecendo o desenvolvimento pós-plantio das mudas.

O ácido jasmônico e seus derivados jasmonatos, originários do ácido linolênico, são reguladores endógenos do crescimento vegetal que ocorrem em várias espécies vegetais e estão relacionados com a senescência de plantas, com a abscisão foliar, com o desenvolvimento de embriões e com mecanismo de defesa, agindo como sinalizadores de estresse (Salisbury \& Ross, 2013; Taiz et al., 2017).

Os estímulos mecânicos por meio de flexões caulinares em mudas podem induzir respostas em vegetais (Jaffe, 1973). Apesar de as respostas vegetais a esses estímulos serem muito variáveis entre espécies, têm sido relatados alguns comportamentos comuns a um grande número de espécies lenhosas. Entre eles estão a redução do alongamento celular, com consequente redução da altura das mudas, e o aumento do diâmetro de coleto, a exemplo do observado em mudas de Ulmus americana L., por Telewski \& Pruyn (1998) e em mudas de Acacia koa A. Gray, por Ishihara et al. (2017). Esses atributos têm servido como indicadores da qualidade de mudas (Fonseca et al., 2002; Gomes et al., 2002; Braam, 2005; Dranski, 2013; Volkweis etal., 2014).

Apesar de a imposição das flexões caulinares e de a aplicação do ácido jasmônico causarem respostas fisiológicas e de estarem relacionadas com rusticidade em mudas florestais, ainda se faz necessário verificar se, de fato, refletem-se em mudas com maior desempenho a campo. Portanto, este trabalho objetivou avaliar a qualidade de mudas de eucalipto, após aplicações de ácido jasmônico e de flexões caulinares e seus reflexos sobre o estabelecimento a campo.

\section{MATERIAL E MÉTODOS}

O experimento foi conduzido no município de Marechal Cândido Rondon, PR, entre maio e outubro de 2016, sendo realizado em duas etapas. A primeira etapa foi conduzida em ambiente protegido, não climatizado. As laterais foram fechadas com tela de $30 \%$ de sombreamento, de coloração branca. A segunda etapa foi realizada a campo, nas coordenadas $24^{\circ} 31^{\prime} \mathrm{S}$ e $54^{\circ} 01^{\prime} \mathrm{O}$, em altitude de $363 \mathrm{~m}$.

O clima da região, segundo Köppen, é caracterizado como tipo Cfa, subtropical, com temperatura média, no mês mais frio, inferior a $18^{\circ} \mathrm{C}$, e temperatura média, no mês mais quente, acima de $22{ }^{\circ} \mathrm{C}$, com geadas pouco frequentes e tendência de concentração das chuvas nos meses de verão, sem estação seca definida. A precipitação pluviométrica anual fica em torno de 1.600 a $1.800 \mathrm{~mm}$ (Caviglione et al., 2000).

Mudas do híbrido Eucalyptus urophylla x Eucalyptus grandis ( $\mathrm{Cl} 1528)$ foram propagadas por via vegetativa, por miniestacas, em tubetes de $50 \mathrm{~cm}^{3}$, preenchidos com substrato comercial a base de casca de pinus, e adubadas com $300 \mathrm{~g}$ de fertilizante de liberação controlada da formulação $\mathrm{N}_{2}-\mathrm{P}_{2} \mathrm{O}_{5}-\mathrm{K}_{2} \mathrm{O}$ (16-8-12). As mudas foram adquiridas do viveiro florestal com idade de 60 dias, altura média de 23,58 $\pm 1,16 \mathrm{~cm}$, diâmetro do coleto médio de 2,70 $\pm 0,13$ $\mathrm{mm}$ e massas de matérias secas do sistema radicular e dos 
tecidos aéreos de 0,2222 g, 0,5798 g, respectivamente. Em maio de 2016, as mudas foram colocadas em ambiente protegido e submetidas aos tratamentos de rustificação por aplicação de ácido jasmônico e de flexões caulinares.

$\mathrm{O}$ clone de eucalipto $\mathrm{Cl} 1528$, conhecido como "superclone", de acordo com o Portal Florestal (2016), apresenta base genética de Eucalyptus urophylla x Eucalyptus grandis, com incremento médio anual (IMA) de $50 \mathrm{~m}^{-3} \mathrm{ha}^{-1}$ ano $^{-1}$, densidade básica da madeira de $531 \mathrm{~kg}$ $\mathrm{m}^{-3}$, teor de lignina total de $29,24 \%$, teor de holocelulose de $68,14 \%$, rendimento gravimétrico de $50,41 \%$ e resistência mecânica de $80,82 \%$. A criação do clone objetivou a obtenção de plantas com bom crescimento, característica do Eucalyptus grandis, assim como com aumento da densidade da madeira e com melhorias do rendimento e das propriedades físicas da celulose, características do Eucalyptus urophylla (Carvalho \& Nahuz, 2001).

O delineamento experimental foi o inteiramente ao acaso, com cinco repetições de 20 mudas, que foram submetidas aos seguintes tratamentos: T1: testemunha; T2: 2,0 ìmol L $\mathrm{L}^{-1}$ de ácido jasmônico, aplicado, semanalmente, por quatro semanas; T3: 4,0 $\mu$ mol de ácido jasmônico, aplicado, semanalmente, por quatro semanas; T4: 6,0 $\mu \mathrm{mol}$ de ácido jasmônico aplicado, semanalmente, por quatro semanas; T5: 8,0 $\mu$ mol de ácido jasmônico aplicado, semanalmente, por quatro semanas; T6: 20 flexões diárias, por quatro semanas; T7: 40 flexões diárias, por quatro semanas. Em todos os tratamentos, foram aplicados água deionizada + tensoativo não iônico, semanalmente, por quatro semanas.

A aplicação do estímulo químico foi realizada sempre no final da tarde (17 h), com intervalos de uma semana, por meio de pulverizações foliares de ácido jasmônico em concentrações de acordo com cada tratamento descrito acima, com volume total da solução equivalente a $7 \mathrm{~mL}$ por muda, até o ponto em que se iniciou o escorrimento foliar. As soluções foram aplicadas com pulverizador costal manual, com a pressão de 0,3 MPa. Durante o período de imposição dos tratamentos, as mudas foram irrigadas, diariamente, por aspersão até a saturação do substrato, duas vezes ao dia: no início da manhã e no final da tarde. As flexões caulinares compreenderam estímulos mecânicos, efetuados, diariamente, por passagem, em duplo sentido, de uma estrutura composta por uma barra de cano de PVC com 25 mm de diâmetro, disposta horizontalmente, fixada em uma estrutura metálica com rolamentos. As mudas foram flexionadas verticalmente não mais do que a $45^{\circ}$, mediante a passagem da barra no terço inferior da folhagem, sempre no mesmo horário, à velocidade de $0,10 \mathrm{~m} \mathrm{seg}^{-1}$ (Volkweis et al., 2014).

Ao término do período dos tratamentos, as 20 mudas por repetição foram utilizadas para as determinações dos incrementos de altura, de diâmetro do coleto e de número de folhas. Quatro mudas por repetição foram selecionadas ao acaso para obtenção dos incrementos das massas secas das raízes e dos tecidos aéreos.

A altura da muda foi medida do nível do substrato até a gema apical e o diâmetro do coleto foi mensurado com paquímetro digital. As massas de matérias secas de raízes e dos tecidos aéreos foram obtidas por secagem em estufa de circulação de ar, a $65^{\circ} \mathrm{C}$, durante $72 \mathrm{~h}$. O incremento do número de folhas foi obtido por contagem de todas as folhas expandidas. Os incrementos foram calculados pelas diferenças entre os valores antes e após a imposição dos tratamentos, ou seja, num intervalo de tempo de quatro semanas.

O índice relativo de clorofila por unidades SPAD final foi obtido da média de quatro folhas por muda, em 20 mudas por repetição, com medidas tomadas no centro da folha, com o medidor Minolta SPAD-502. O potencial de regeneração de raízes foi obtido por meio do plantio de quatro mudas por repetição, ao final da aplicação dos tratamentos, em vasos de $3,4 \mathrm{dm}^{3}$, preenchidos com areia. As mudas permaneceram nos vasos por 28 dias, sob irrigação diária até a capacidade de campo. Após este período, foi quantificada a massa de matéria seca de novas raízes, emergidas do torrão, em uma planta por parcela (Landis et al., 2010).

Após o período de rustificação das mudas, deu-se início à segunda etapa, sendo três mudas (das 20) por repetição plantadas a campo, seguindo-se o delineamento em blocos ao acaso, respeitando-se os tratamentos impostos durante a fase de rustificação.

O plantio das mudas ocorreu em julho de 2016. O clima da região é classificado como Cfa - clima subtropical úmido mesotérmico (Caviglione et al., 2000). Os dados meteorológicos do período que compreendeu a condução do experimento a campo estão apresentados na Figura 1. De acordo com mapa de solos do Estado do Paraná (Bhering et al., 2007), o solo do local é classificado como LATOSSOLO VERMELHO distroférrico típico, textura muito argilosa (Santos et al., 2013), apresentando as seguintes características químicas na camada de $0-20 \mathrm{~cm}$ de profundidade, antes do plantio: $\mathrm{pH}\left(\mathrm{CaCl}_{2}\right)=5,3 ; \mathrm{MO}=$ $13,40 \mathrm{~g} \mathrm{dm}^{-3} ; \mathrm{P}=1,32 \mathrm{mg} \mathrm{dm}^{-3} ; \mathrm{Ca}^{2+}=4,30 \mathrm{cmol}_{\mathrm{c}} \mathrm{dm}^{-3} ; \mathrm{Mg}^{2+}$ $=2,20 \mathrm{cmol}_{\mathrm{c}} \mathrm{dm}^{-3} ; \mathrm{K}^{+}=0,23 \mathrm{cmol}_{\mathrm{c}} \mathrm{dm}^{-3} ; \mathrm{Al}^{3+}=0,0 \mathrm{cmol} \mathrm{dm}_{\mathrm{c}}^{-}$ 3; $\mathrm{H}+\mathrm{Al}=3,42 \mathrm{cmol}_{\mathrm{c}} \mathrm{dm}^{-3} ; \mathrm{SB}=6,73 \mathrm{cmol}_{\mathrm{c}} \mathrm{dm}^{-3} ; \mathrm{CTC}=$ $10,15 \mathrm{cmol}_{\mathrm{c}} \mathrm{dm}^{-3} \mathrm{e} \mathrm{V} \%=66,31 \%$.

As covas para o plantio das mudas a campo mediram $27 \mathrm{~cm}$ de diâmetro por $50 \mathrm{~cm}$ de profundidade, em espaçamento de 3 x $2 \mathrm{~m}$. A adubação de base foi de $100 \mathrm{~g}$ por cova da formulação $5 \mathrm{~N}-25 \mathrm{P}_{2} \mathrm{O}_{5}-25 \mathrm{~K}_{2} \mathrm{O}$. Plantas daninhas foram eliminadas por meio de capinas e roçadas, a cada 30 dias. Para o combate de formigas cortadeiras, foram utilizadas iscas granuladas (sulfluramida $0,3 \%$ ), seguindo-se as recomendações da embalagem comercial. 
Aos 90 dias após o plantio, foram avaliados os incrementos de altura e de diâmetro do coleto e a relação altura/ diâmetro das mudas.

A análise dos dados consistiu primeiramente na avaliação da normalidade da distribuição dos resíduos, pelo teste de Lilliefors, e da homogeneidade da variância, pelo teste de Cochran e Bartlet. Em seguida, foram determinadas as matrizes de distância euclidiana média padronizada, utilizadas como medidas de dissimilaridade para a análise de agrupamento dos tratamentos pelo método hierárquico UPGMA (Unweighted Pair Group Method using Arithmetic averages) (Ribeiro Júnior \& Melo, 2008). Para a determinação do ponto de corte no dendrograma, foi utilizado o método de Mojena (1977), que é um procedimento baseado no tamanho relativo dos níveis de fusões ou distâncias no dendrograma. A importância relativa das características na composição dos grupos foi calculada pelo método de Singh (1981). As análises e construção do dendrograma foram realizadas, utilizando-se os softwares SAEG 9.1 (UFV, 2007) e o XLSTAT (Addinsoft, 2009).

Utilizou-se a análise de variância para delineamento inteiramente ao acaso, para dados não balanceados, a 5\% de significância, para testar a hipótese da diferença entre grupos para cada parâmetro de qualidade avaliado no viveiro e a campo. A média dos grupos foi representada, em gráfico de perfis com base no teste de Tukey a 5\% de significância.

\section{RESULTADOS E DISCUSSÃO}

A análise de agrupamento dos tratamentos pelo método hierárquico UPGMA evidenciou a formação de três grupos: grupo 1, composto por quatro tratamentos [testemunha (T1), dose menor de ácido jasmônico (T2) e doses intermediárias de ácido jasmônico T3 e T4]; grupo 2, composto apenas pelo tratamento da dose maior de ácido jasmônico (T5) e grupo 3, composto pelos tratamentos das flexões caulinares (T6 e T7) (Figura 2). Esses resultados na separação dos grupos sugerem que as mudas do clone 1528 de eucalipto, submetidas à aplicação de ácido jasmônico, bem como a testemunha, externaram respostas morfológicas que não se assemelham àquelas resultantes das flexões caulinares, diferentemente do encontrado por Cadorin et al. (2015) em mudas de Cordia trichotoma (Vell.) Arrab. ex Steud.

A variável que apresentou maior contribuição relativa para a formação dos grupos foi IA (incremento de altura) com $38,1 \%$, seguida pelo NF (número de folhas) com $19 \%$, IDC (incremento de diâmetro do coleto) com 14,3\%, PRR (potencial de regeneração de raízes) e IMSPA (incremento da massa seca da parte aérea), ambos com 9,52\%, e IMSR e SPAD, ambos com 4,76\%.

Em relação aos parâmetros quantificados no viveiro, todos apresentaram diferença significativa $(\mathrm{p}<0,05)$ entre os grupos. As mudas de eucalipto que receberam as flexões caulinares (grupo III) apresentaram menor incre-

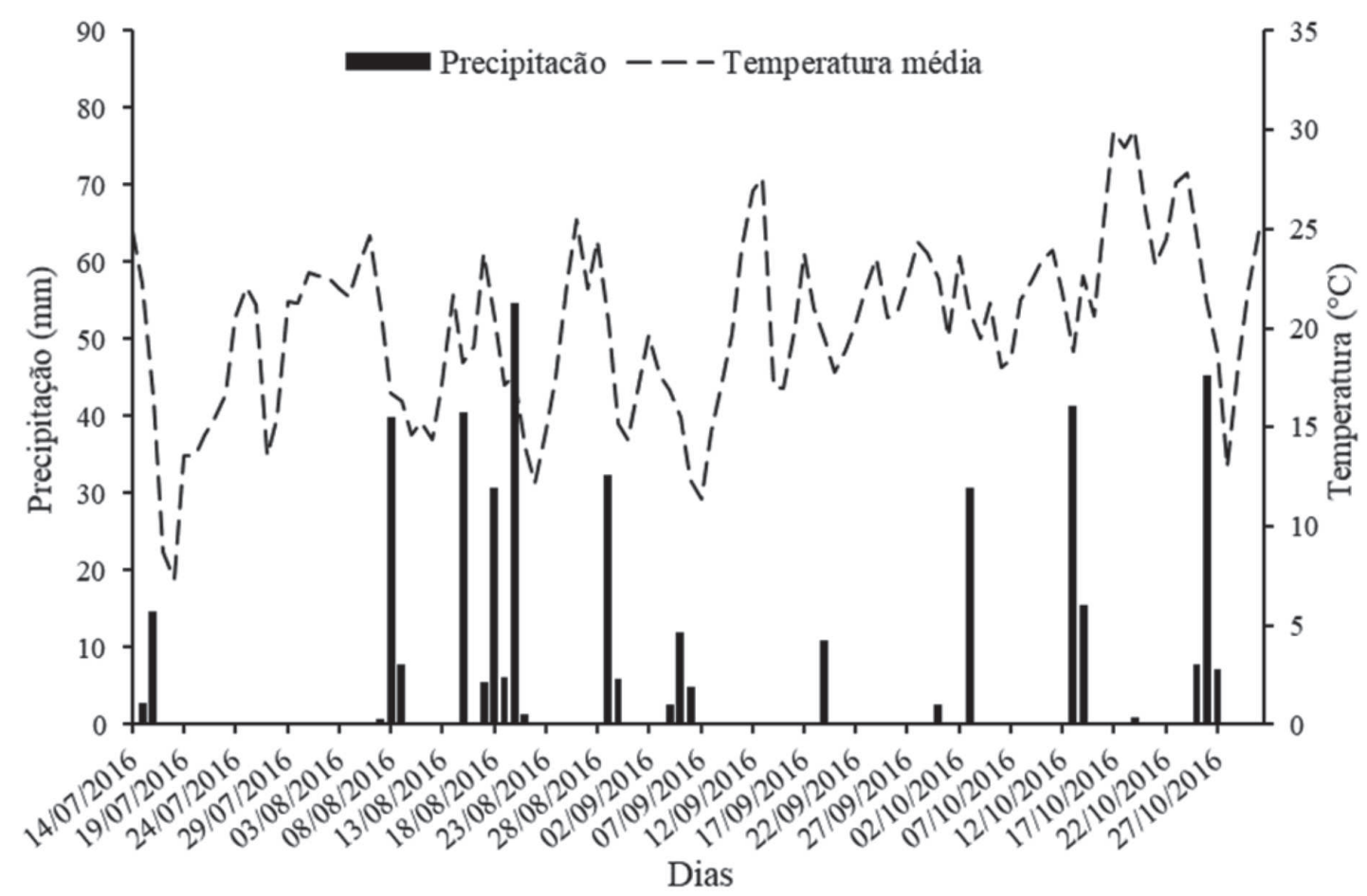

Fonte: Estação Meteorológica de Observação de Superfície Automática do INMET.

Figura 1: Precipitação pluviométrica e temperatura média, na estação automática de Marechal Cândido Rondon, PR, entre os meses de julho e de outubro de 2016. 


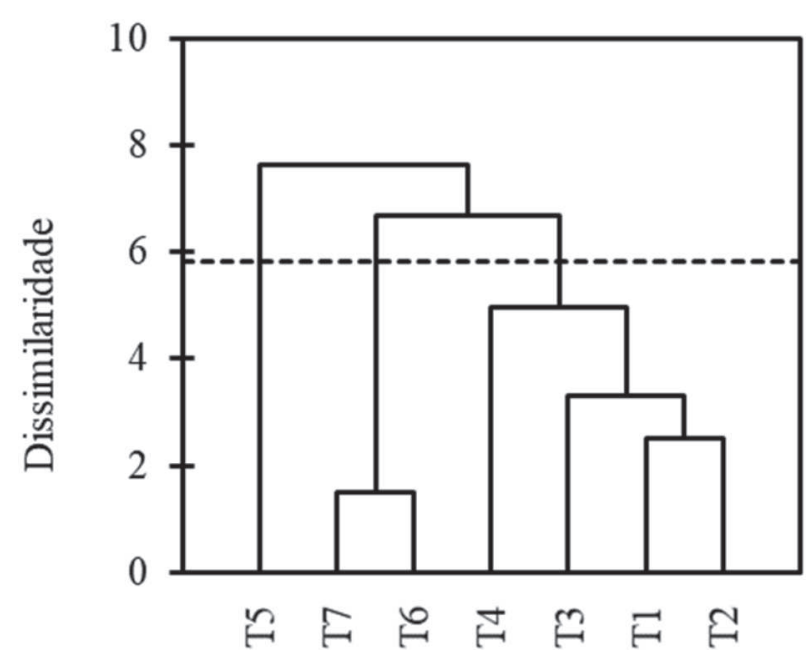

Figura 2: Dendrograma obtido pelo método UPGMA, a partir das medidas de dissimilaridade entre tratamentos rustificativos aplicados em mudas de Eucalyptus urophylla x Eucalyptus grandis, com base na distância euclidiana média padronizada, em que: T1- testemunha: T2 - 2,0 $\mu \mathrm{mol} \mathrm{L}^{-1}$; T3 - 4,0 $\mu \mathrm{mol} \mathrm{L}^{-1}$; T4 $-6,0 \mu \mathrm{mol} \mathrm{L}-1$; T5 - 8,0 $\mu \mathrm{mol} \mathrm{L}^{-1}$; T6 - 20 flexões caulinares; T7 -40 flexões caulinares.

mento de altura (Figura 3a). As mudas que receberam as demais doses do ácido jasmônico, juntamente com a testemunha (grupos I e II) não apresentaram diferença significativa ( $p \geq 0,05)$. Mudas do grupo III, contudo, apresentaram IDC maior que o das mudas do grupo II, sem diferirem do grupo I (Figura 3b).

Estímulos mecânicos (flexões caulinares) podem ser responsáveis por desencadear uma série de respostas em mudas de espécies lenhosas. Dentre elas, o menor incremento de altura e o maior incremento de diâmetro de coleto têm sido comumente relatados para diversas espécies lenhosas, como para Cordia trichotoma, Populus trichocarpa (Torr.; A. Gray), Populus deltoides (Bartr. ex Marsh, Pinus taeda L., após submissão à ação mecânica, por causa da redução do alongamento celular (Kern et al., 2005; Dranski, 2013; Volkweis et al., 2014; Dranski et al., 2015; Cadorin et al., 2015). Essas alterações podem estar relacionadas com o fato de esses estímulos causarem perturbações mecânicas (estresse) e, por sua vez, abrandarem o crescimento primário e estimularem o crescimento secundário das plantas (Morel et al., 2012).

Para eucalipto inexistem trabalhos com este objetivo na literatura, porém encontram-se trabalhos semelhantes com outras espécies. Trabalhando com mudas de $C$. trichotoma, Cadorin et al. (2015) verificaram menor incremento de altura de mudas submetidas a flexões caulinares (76\% inferior), enquanto mudas pulverizadas com metil jasmonato apresentaram redução média de $42 \%$, em relação ao tratamento controle. Ainda de acordo com os autores acima citados, a aplicação de flexões caulinares e de metil jasmonato elevou, em média, a taxa de crescimento, em diâmetro, do coleto em $102 \%$ a mais que a do tratamento controle. Dranski et al. (2015), trabalhando com mudas de P. taeda, verificaram incremento médio de $28 \%$ de diâmetro do caule, em mudas sob frequências de 10 a 40 flexões caulinares.

Resultados que, em parte, corroboram os deste estudo, foram encontrados por Kern et al. (2005), que, após submeterem sete híbridos de $P$. trichocarpa e $P$. deltoides a 20 flexões caulinares diárias, por 80 dias, encontraram reduções de altura, de biomassa aérea e aumento de diâmetro de coleto para todos os híbridos, em comparação com os da testemunha. As alterações resultantes dos incrementos de altura e de diâmetro de coleto, resultantes tanto da aplicação de flexões caulinares quanto da de metil jasmonato, parecem estar relacionadas com a síntese de etileno, ao passo que Biro \& Jaffe (1984) afirmaram que perturbações mecânicas, tanto na forma de atrito como de ferimento, induzem à síntese de etileno em entrenós de Phaseolus vulgaris (L. cv. Cherokee Wax).

Mudas que compõem o grupo II apresentaram o maior incremento em IMSPA (Figura 3c). Já, com a variável IMSR, os grupos II e III não diferiram entre si, porém, ambos obtiveram maiores incrementos do que o grupo I (Figura $3 d)$. Estes resultados se devem ao fato de a maior dose do ácido jasmônico ter contribuído para desenvolvimento da parte área e não tenha afetado o desenvolvimento radicular das mudas do clone de eucalipto. Segundo Creelman \& Mullet, (1997), as maiores concentrações de jasmonato estão presentes em tecidos jovens e em crescimento, mostrando sua importância como estimulador do desenvolvimento vegetal.

A taxa de incremento do NF foi menor no grupo III do que nos demais grupos. Essa constatação mostra que as mudas do clone 1528 , submetidas a flexões caulinares, externaram decréscimo do número de folhas em relação ao NF dos demais grupos (Figura 4a). O estresse proporcionado pelas flexões caulinares fez que as mudas perdessem folhas e, por consequência, sofressem diminuição da área foliar, afetando a área fotossintética da muda, fato esse que pode ter contribuído para desempenho inferior, após os 90 dias do plantio a campo, das mudas submetidas às flexões caulinares no viveiro. Resposta que corrobora a deste estudo foi verificada por Shannon \& Thomas (2018), que, estudando estresse induzido pela remoção de folhas e de folhagem em completa escuridão em $P$. taeda L., constataram que a desfolhação ou o estresse, induzido pelo sombreamento em um ou mais ramos, reduziu o crescimento do diâmetro. Vários estudos também relataram a redução global do diâmetro do caule após estresse induzido pela desfolha artificial (Handa $e t$ al., 2006; Susiluoto et al., 2010), ou estresse induzido pela sombra (Dong et al., 2015). Portanto, pode-se dizer que a diminuição da área foliar é fator limitante do desenvolvi- 
mento da muda a campo, como observado neste estudo. O maior valor do índice relativo de clorofila, expresso por unidades SPAD (Figura 4b), foi mensurado em folhas de mudas do grupo III. Segundo Taiz et al. (2017), tecidos vegetais submetidos a qualquer situação de estresse podem apresentar aumento da atividade da peroxidase, desencadeando processos fisiológicos que culminam na proteção celular contra reações oxidativas, na lignificação da parede celular, na oxidação de compostos fenólicos, na biossíntese de etileno e na manutenção da integridade das membranas. Portanto, os resultados deste estudo mostram que as flexões caulinares provocaram estresse, o que contribuiu para menor crescimento em altura e menor número de folhas e, por consequência, maior concentração do teor de clorofila nas folhas. Corroborando os deste estudo, resultados obtidos por Saidi et al., (2009) que testaram a aplicação de flexões caulinares em Solanum lycopersicum verificaram resposta da planta ao estresse mecânico, pela inibição do alongamento dos entrenós, relacionada com a indução da atividade provocada pelo aumento das atividades da desidrogenase do álcool
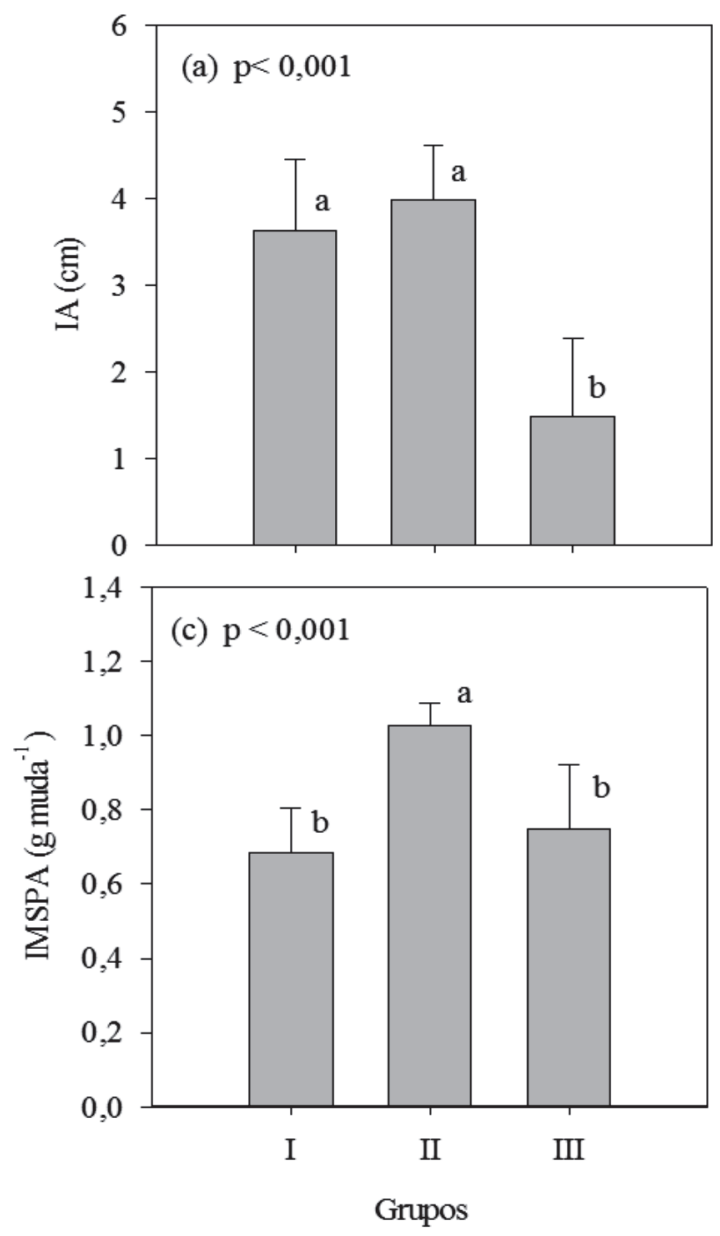

cinamílico e das diferentes formas da peroxidase. Relatam também que uma nova isoforma de peroxidase, expressa, em plantas flexionadas, e o aumento da peroxidase, expresso em plantas controle, sugerem um possível papel dessas isoformas no processo de lignificação, o que se acredita estar envolvido na inibição do crescimento de plantas. O PRR foi maior nas mudas pertencentes ao grupo III que nas do grupo I, que por sua vez não diferiu do grupo II (Figura 4c). Esses resultados atestam que mudas submetidas às flexões caulinares tiveram a produção de novas raízes estimuladas. O teste de potencial de regeneração de raízes é considerado por muitos pesquisadores como preditivo do desempenho da muda a campo, e tem sido um bom indicador de qualidade de mudas, uma vez que seu resultado é a expressão de vários parâmetros fisiológicos, que culminam na habilidade de uma muda para iniciar e alongar novas raízes, em um dado período de tempo e em condição ambiental tida como ótima para o crescimento (Davis \& Jacobs, 2005; Landis et al., 2010). Desta forma, a capacidade de crescimento de novas raízes é determinante para que ocorra a conexão entre o sistema
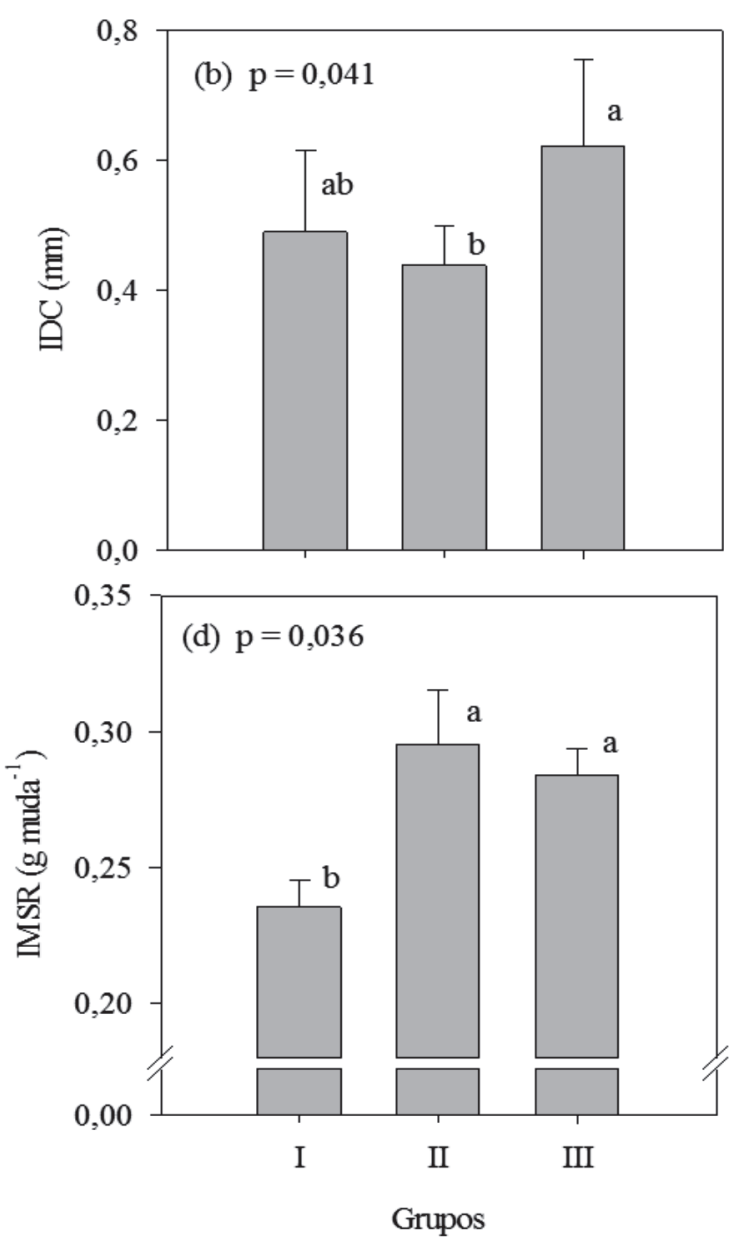

Figura 3: IA: incremento de altura (a); IDC: incremento de diâmetro do coleto (b); IMSPA: incremento de massa seca da parte aérea (c); IMSR: incremento da massa seca da raiz (d), em mudas de Eucalyptus urophylla $x$ Eucalyptus grandis, rustificadas por meio de doses de ácido jasmônico e de flexões caulinares, ao final do período de rustificação. Grupos não seguidos de mesma letra minúscula diferem estatisticamente entre si pelo teste Tukey a 5\% de probabilidade de erro. Barras referem-se ao desvio padrão. 
radicular da muda com o solo do local de plantio (Grossnickle, 2012).

Vários trabalhos têm indicado que o metil ester do ácido jasmônico induz a produção de etileno em diversos órgãos das plantas (Fan et al., 1998). Hudgins \& Franceschi (2004) aplicaram diferentes concentrações de metil jasmonato no segundo nó de mudas de Pseudotsuga menziesii (Mirbel) Franco var. menziesii e encontraram indução de produção de etileno nos entrenós acima e abaixo do nó tratado. O etileno, por sua vez, pode provocar redução de crescimento de plantas por promover, além da redução do transporte de auxinas, a reorganização de microtúbulos e microfibrilas de celulose da parede celular para uma posição longitudinal, resultando em redução de altura e em espessamento do caule (Taiz et al., 2017). Porém, esses resultados foram diferentes do encontrado neste estudo, em que a maior dose aplicada do ácido jasmônico (grupo II) proporcionou maior IMSPA (Figura 3c). Em contraponto, estímulos mecânicos por meio de flexões caulinares proporcionaram mudas com menor crescimento da parte aérea, porém, com maior IDC.
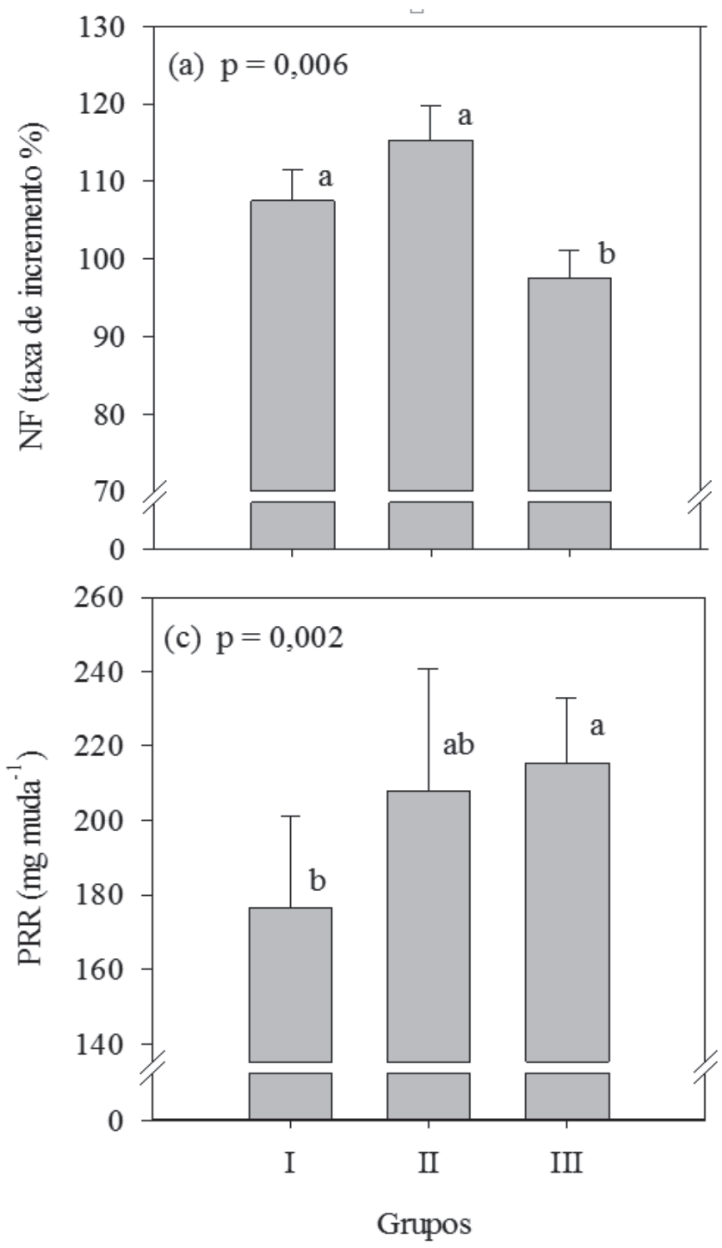

A partir dos resultados apresentados, é possível afirmar que a aplicação das flexões caulinares (grupo III) possibilitou a obtenção de mudas com maior rusticidade em relação ao diâmetro do coleto, ao IMSR, ao SPAD e ao PRR, porém, tendo o crescimento aéreo afetado em relação ao dos grupos I e II. Estes fatos caracterizam que a utilização do ácido jasmônico não substitui a utilização das flexões caulinares em mudas do clone 1528 de eucalipto, visto que as respostas morfométricas quantificadas neste trabalho não se assemelharam.

Em relação ao desempenho das mudas a campo, aos 90 dias após o plantio, o grupo I apresentou maior IA do que o grupo III, porém ambos não diferiram $(\mathrm{p} \geq 0,05)$ do grupo II (Figura 5a). Já, para o IDC, os grupos I e II obtiveram maior ganho no campo do que o grupo III. (Figura $5 b)$. Para a relação altura/diâmetro (H/D), não houve diferença significativa entre os grupos avaliados $(\mathrm{p}=0,796)$.

Os resultados observados em mudas submetidas à aplicação dos estímulos mecânicos sustentam a hipótese de que a redução do crescimento aéreo está associada à redução da fotossíntese, seja pelo estímulo à abscisão

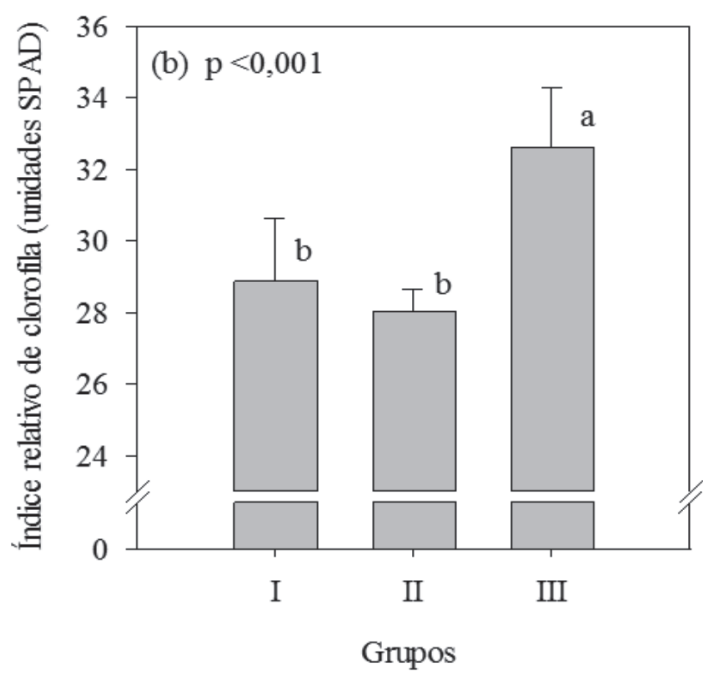

Figura 4: NF: número de folhas (a); SPAD: índice relativo de clorofila (b); PRR: potencial de regeneração das raízes (c); em mudas de Eucalyptus urophylla x Eucalyptus grandis, rustificadas por meio de doses de ácido jasmônico e de flexões caulinares, ao final do período de rustificação. Grupos não seguidos de mesma letra minúscula diferem estatisticamente entre si pelo teste Tukey a 5\% de probabilidade de erro. Barras referem-se ao desvio padrão.

Rev. Ceres, Viçosa, v. 65, n.5, p. 424-432, set/out, 2018 

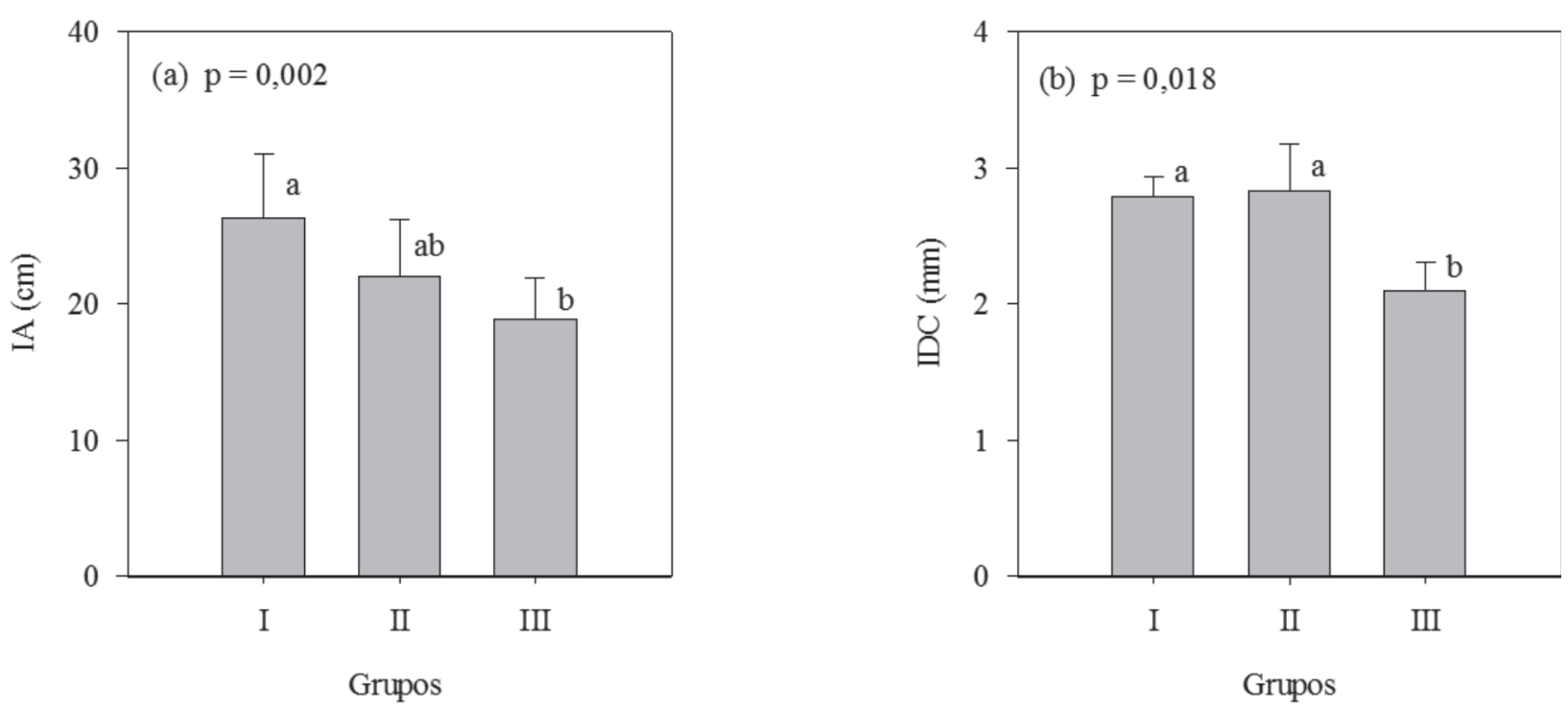

Figura 5: IA: incremento de altura (a); IDC: incremento de diâmetro do coleto (b); de Eucalyptus urophylla x Eucalyptus grandis, aos 90 dias do plantio. Grupos não seguidos de mesma letra minúscula diferem estatisticamente entre si pelo teste Tukey a 5\% de probabilidade de erro. Barras referem-se ao desvio padrão.

foliar ou pelas reduções em tamanho e em número de folhas, conforme também descrito por Dranski (2013).

Ao se verificar o desempenho das mudas a campo, após os 90 dias do plantio, nota-se que as mudas submetidas às flexões caulinares (grupo III) apresentaram desempenho menor do que os dos grupos I e II, mostrando que, para as condições estudadas, as mesmas apresentaram taxa de crescimento a campo menor do que a das mudas submetidas à aplicação de ácido jasmônico, bem como menor que a da testemunha. Esses resultados podem estar ligados às duas variáveis com maiores contribuições relativas na composição dos grupos, sendo elas o IA e a NF, com 38,1 e 19\%, respectivamente, visto que, ainda no viveiro, mudas do grupo III apresentaram menor IA e NF. Vale ressaltar que talvez com mais tempo de experimento no campo e, ou, caso houvesse ocorrido uma situação de estresse hídrico severo durante o período de estudo, os resultados encontrados poderiam ser diferentes, visto que, mesmo o PRR sendo considerado por muitos pesquisadores como preditivo do desempenho da muda a campo, isso não foi evidenciado neste estudo.

Os resultados a campo foram inesperados, pois mesmo não se tratando da mesma espécie, diferem do exposto na literatura por vários autores (Kern et al., 2005; Dranski, 2013; Volkweis et al., 2014; Dranski et al., 2015; Cadorin et al., 2015), visto que mudas do grupo III apresentaram maior IDC que o das mudas do grupo II e maior PRR que o das mudas do grupo I e não apresentaram maiores IA e IDC a campo. De acordo com este estudo, não é possível afirmar que mudas de Eucalyptus urophylla x Eucalyptus grandis, que atestaram maiores IDC, PRR e SPAD durante a rustificação no viveiro, apresentarão maiores IA e IDC a campo, após 90 dias do plantio. A redução de altura, o crescimento de novas raízes e o incremento de diâmetro, durante o desenvolvimento das mudas no viveiro, não se refletem em maior qualidade a campo, para este clone durante o período de avaliação, nas condições estudadas. É importante relatar que, durante os 90 dias após o plantio, não se verificaram mudas com sintomas de mortalidade aparente (mudas totalmente secas).

\section{CONCLUSÕES}

Mudas de Eucalyptus urophylla x Eucalyptus grandis, submetidas a estímulo mecânico por meio de flexões caulinares (grupo III), não externaram maior crescimento após 90 dias de plantio no campo;

Mudas de Eucalyptus urophylla x Eucalyptus grandis com maior incremento de altura e de número de folhas após a rustificação apresentaram maiores incrementos de altura e de diâmetro do coleto, após 90 dias de plantio no campo;

Os resultados de estímulos mecânicos, por meio de flexões caulinares e de estímulo químico, por meio do ácido jasmônico, aplicados em mudas de Eucalyptus urophylla x Eucalyptus grandis, não se assemelham, quanto aos parâmetros estudados. Portanto, o uso de um estímulo não substitui o do outro, nas condições estudadas.

\section{REFERÊNCIAS}

Addinsoft SARL (2009) XLSTAT software. version 9.0. Paris, Addinsoft. CD-ROM.

Bhering SB, Santos HG, Manzatto CV, Bognola I, Fasolo PJ, Carvalho AP, Potter O \& Curcio G (2007) Mapa de solos do Estado do Paraná: escala 1:250.000: legenda. Rio de Janeiro, Embrapa Solos. 73p. 
Biro R \& Jaffe MJ (1984) Thigmomorphogensis: ethylene evolution and its role in the changes observed in mechanically perturbed bean plants. Physiologia Plantarum, 62:289-296.

Braam J (2005) In touch: respostas das plantas aos estímulos mecânicos. New Phytologist, 165:373-389.

Cadorin DA, Malavasi UC, Coutinho PWR, Dranski JAL \& Malavasi MM (2015) Metil jasmonato e flexões caulinares na rustificação e crescimento inicial de mudas de Cordia trichotoma. Cerne, 21:657-664.

Carvalho AM \& Nahuz MAR (2001) Valorização da madeira do híbrido Eucalyptus grandis x Eucalyptus urophylla através da produção conjunta de madeira serrada em pequenas dimensões, celulose e lenha. Scientia Forestalis, 59:61-76.

Caviglione JH, Kiihl LRB, Caramori PH \& Oliveira D (2000) Cartas climáticas do Paraná. Londrina, IAPAR. CD-ROM.

Creelman RA \& Mullet JE (1997) Biosynthesis and action of jasmonate in plants. Annual Review of Plant and Molecular Biology, 48:355-381.

Davis AS \& Jacobs DF (2005) Quantifying root system quality of nursery seedlings and relationship to out planting performance. New Forests, 30:295-311.

Dranski JAL, Malavasi UC \& Malavasi MM (2015) Relationship between lignin content and quality of Pinus taeda seedlings. Revista Árvore, 39:905-913.

Dranski JAL (2013) Tigmomorfogênese na rustificação e sobrevivência em mudas de Pinus taeda L. Tese de Doutorado. Universidade Estadual do Oeste do Paraná, Marechal Cândido Rondon. $107 \mathrm{p}$.

Dong T, Li J, Zhang Y, Korpelainen H, Niinemets Ü \& Li C (2015) Partial shading of lateral branches affects growth and foliage nitrogen and water use efficiencies in the conifer Cunninghamia lanceolate growing in a warm monsoon climate. Tree Physiology, 35:632-643.

Fan X, Matheis JP \& Fellman JK (1998) A role for jasmonates in climacteric fruit ripening. Planta, 204:444-449.

Fonseca EP, Valéri SV, Miglioranza E, Fonseca N \& Couto L (2002) Padrão de qualidade de mudas de Trema micrantha (L.) Blume, produzidas sob diferentes períodos de sombreamento. Revista Árvore, 26:515-523.

Salisbury FB \& Ross CW (2013) Fisiologia das plantas. 4ª ed. São Paulo, Cengage Learning. 792p.

Gomes JM, Couto L, Leite HG, Xavier A \& Garcia SLR (2002) Parâmetros morfológicos na avaliação da qualidade de mudas de Eucalyptus grandis. Revista Árvore, 26:655-664.

Gonçalves KS, Sousa AP \& Velini EDS (2015) Aplicação de reguladores vegetais e de fosfito de potássio em mudas de eucalipto submetidas à deficiência hídrica. Irriga, 20:273-285.

Grossnickle SC (2012) Why seedlings survive: influence of plant attributes. New Forests, 43:711-738.

Handa IT, Körner C \& Hättenschwiler S (2006) Conifer stem growth at the altitudinal treeline in response to four years of $\mathrm{CO}_{2}$ enrichment. Global Change Biology, 12:2417-2430.

Hudgins JW \& Franceschi RV (2004) Methyl jasmonate-induced ethylene production is responsible for conifer phloem defense responses and reprogramming of stem cambial zone for traumatic resin duct formation. Plant Physiology, 135:21342149 .

Ishihara KL, Lee EKW \& Borthakur D (2017) Thigmomorphogenesis: changes in morphology, biochemistry, and levels of transcription in response to mechanical stress in Acacia koa. Canadian Journal of Forest Research, 47:583-593.
Jaffe MJ (1973) Thigmomorphogenesis: the response of plant growth and development to mechanical stimulation. Planta, 114:143-156.

Landis TD, Dumroese RK \& Haase DL (2010) The container tree nursery manual: seedling processing, storage, and out planting. Washington, Department of Agriculture Forest Service. 200p.

Kern AK, Wers WF, Telewski WF \& Koehler L (2005) Mechanical perturbation affects conductivity, mechanical properties and aboveground biomass of hybrid poplars. Tree Physiology, 25:1243-1251.

Mazzuchelli EHL, Souza G \& Pacheco AC (2014) Rustificação de mudas de eucalipto via aplicação de ácido salicílico. Pesquisa Agropecuária Tropical, 44:443-450.

Mojena R (1977) Hierarchical grouping methods and stopping rules: an evaluation. The Computer Journal, 20:359-363.

Morel P, Crespel L, Galopinc G \& Mouliad B (2012) Effect of mechanical stimulation on the growth and branching of garden rose. Scientia Horticulturae, 135:59-64.

Oro P, Volkweis RC, Neiverth W, Dranski JAL, Malavasi UC \& Malavasi MM (2011) Aplicação de regulador vegetal na aclimatação de mudas de Cariniana estrellensis. Cultivando o Saber, 5:103-112.

Portal Florestal (2015) Clone - AEC 1528 - Super Clone. Disponível em: <http://www.portalflorestal.com.br/portfolio/mudasde-eucalipto-clonado-a-venda-clone-aec-1528-super-clone/>. Acessado em: 08 de novembro de 2016.

Ribeiro Júnior JI \& Melo ALP (2008) Guia prático para utilização do SAEG. Viçosa, Folha. 288p.

UFV - Universidade Federal de Viçosa (2007) SAEG: Sistema para Análises Estatísticas. versão 9.1. Viçosa, Fundação Arthur Bernardes. CD-ROM.

Saidi I, Ammar S, Demont-Caulet N, Thévenin J, Lapierre C, Bouzid S \& Jouanin L (2009) Thigmomorphogenesis in Solanum lycopersicum: morphological and biochemical responses in stem after mechanical stimulation. Plant Science, 177:01-06.

Santos HG, Jacomine PKT, Anjos LHC, Oliveira VA, Lumbreras JF, Coelho MR, Almeida JÁ, Cunha TJF \& Oliveira JB (2013) Sistema brasileiro de classificação de solos. $3^{a}$ ed. Brasília, Embrapa. 353p.

Shannon DK \& Thomas JD (2018) Growth of tree diameter and stem taper as affected by reduced leaf area on selected branch whorls. Canadian Journal of Forest Research, 48:317-323.

Singh D (1981) The relative importance of characters affecting genetic divergence. Indian Journal of Genetic and Plant Breeding. New Delhi, 41:237-245.

Susiluoto S, Hilasvuori E \& Berninger F (2010) Testing the growth limitation hypothesis for subarctic Scots pine. Journal of Ecology, 98:1186-1195

Taiz L, Zeiger E, Moller IM \& Murphy A (2017) Fisiologia e desenvolvimento vegetal. $6^{\mathrm{a}}$ ed. Porto Alegre, Artmed. 954p.

Telewski FW \& Pruyn ML (1998) Thigmomorphogenesis: a dose response to flexing in Ulmus americana seedlings. Tree Physiology, 18:65-68.

Volkweis RC, Dranski JAL, Oro P, Malavasi UC \& Malavasi MM (2014) Efeito da tigmomorfogênese na morfometria de mudas de Maytenus ilicifolia (Schrad.) Planch. Ciência Florestal, 24:339-342.

Rev. Ceres, Viçosa, v. 65, n.5, p. 424-432, set/out, 2018 